\title{
SISTEM PENDUKUNG KEPUTUSAN PENGADAAN RAW MATERIAL PEMBUATAN MIE INSTAN MENGGUNAKAN METODE ANALITYCAL HIERARCHY PROCESS (AHP) STUDI KASUS PT.INDOFOOD CBP SUKSES MAKMUR
}

\author{
Dzulkifli Fitriana, Arie S. M Lumenta, Oktavian A Lantang \\ Teknik Informatika, Universitas Sam Ratulangi, Manado, Indonesia. \\ Email: DzulkifliUTD@gmail.com, al@unsrat.ac.id, oktavian@unsrat.ac.id
}

\begin{abstract}
Abstrak --- Penelitian yang berjudul "Sistem Pendukung Keputusan Pengadaan Raw Material Pembuatan Mie instan Menggunakan Metode Analitycal Hierarchy Process (AHP) Studi Kasus PT. Indofood CBP Sukses Makmur” ini bertujuan untuk menghasilkan Sistem Pendukung Keputusan yang objektif dan sistematis dalam menentukan pemilihan bahan baku dengan kualifikasi terbaik dari beberapa produsen bahan baku. kriteria dan seleksi supplier yang digunakan dalam penelitian mengacu pada model QCDFR dimana terdapat lima kriteria yaitu Quality, Cost, Delivery, Flexibility dan Responsivness. Metode yang digunakan sebagai tahapan penelitian ini adalah metode Waterfall model klasik yang bersifat sistematis, berurutan dalam membangun software. Data yang dijadikan sebagai acuan persyaratan kebutuhan sistem yang dibangun didapatkan dari wawancara terhadap kepala bagian gudang, kepala bagian raw material, dan manager pengadaan bahan baku. Dari data hasil wawancara tersebut didapatkan masalah kurangnya objektifitas dan transparansi informasi dalam proses pemilihan bahan baku dari produsen terbaik yaitu belum adanya sebuah standar atau sistem yang digunakan dalam penentuan pengadaan bahan baku dan hanya menggunakan cara pemilihan manual sehingga pemesanan bahan baku ditentukan secara subyektif. Dengan latar belakang tersebut, maka diperlukan Sistem Pendukung Keputusan yang dapat menjadi penunjang bagi proses pengadaan bahan baku.
\end{abstract}

Kata kunci - Sistem Keputusan, Waterfall, AHP, Indoofood, material.

\section{PENDAhUluan}

Perkembangan teknologi yang semakin pesat disegala bidang termasuk bidang industry, perusahaan secara kompetitif bersaing agar tetap bertahan dengan kondisi tersebut. Kepuasan konsumen merupakan hal penting agar perusahaan dapat tetap bertahan. Untuk itu perusahaan harus dapat memenuhi keinginan dan kebutuhan konsumen. Dalam perusahaan manufaktur, ketepatan waktu pengiriman barang kepada konsumen serta mutu suatu produk sangat penting karena hal tersebut dapat meningkatkan kepuasan konsumen. Ketepatan pengiriman barang kepada konsumen sangat dipengaruhi oleh bahan baku yang tersedia tepat waktu, sehingga proses pengambilan keputusan pengadaan bahan baku yang tepat merupakan suatu aktivitas yang penting dalam perusahaan.

Seiring perkembangan ilmu pengetahuan dan teknologi (iptek) yang semakin maju, komputerisasi telah menjadi kebutuhan bagi perusahaan. Kemampuan komputer dalam menyimpan informasi dapat dimanfaatkan tanpa harus bergantung kepada hambatan-hambatan yang dimiliki pada manusia. Dengan menyimpan data dan aturan penalaran yang memadai memungkinkan komputer memberikan kesimpulan atau mengambil keputusan yang kualitasnya sama dengan kemampuan seorang ahli bidang keilmuan tertentu.

Pengambilan keputusan memiliki peranan yang sangat penting bagi perusahaan, kesalahan pengambilan keputusan dapat mempengaruhi kegiatan perusahaan seperti terganggunya proses produksi, meningkatnya biaya yang dikeluarkan perusahaan, atau bahkan kerugian bagi perusahaan. Ketersediaan bahan baku dan pengadaan bahan baku yang tepat dan sesuai dengan yang dibutuhkan tentunya menjadi pertimbangan penting untuk kelancaran proses produksi perusahaan. Pengadaan bahan baku pada PT. Indofood masih dilakukan secara manual, keputusan pengadaan bahan baku masih berdasarkan kebiasaan atau adanya kontrak dengan produsen bahan baku tertentu.

Dengan adanya perencanaan pengadaan bahan baku secara komputerisasi, diharapkan perusahaan bisa mempertimbangkan produsen lain yang mungkin akan lebih menguntungkan perusahaan tentunya dengan perhitungan pertimbangan yang sistematis.

Berdasarkan uraian di atas, dapat diketahui perihal pentingnya sistem pendukung keputusan pengadaan bahan baku dalam suatu perusahaan. Untuk itu penulis mengambil penelitian dengan judul "Sistem Pendukung Keputusan Pengadaan Raw Material Pembuatan Mie Instan menggunakan Metode Analitycal Hierarchy Procces (AHP) dengan study kasus PT.Indofood CBP Sukses Makmur. Dalam aplikasi ini penulis menggunakan model QCDFR sebagai acuan kriteria yang akan di gunakan dalam penilaian pendukung keputusan pengadaan raw material. Model QCDFR adalah kriteria dan seleksi supplier yang di gunakan, terdiri dari 5 kriteria yaitu Quality, Cost, Delivery, Flexibility, dan Responsivenes.

\section{LANDASAN TEORI}

\section{A. Sistem Pendukung Keputusan}

Beberapa definisi Sistem Pendukung Keputusan yang dikemukakan para ahli adalah sebagai berikut :

Menurut Finlay, dkk (1994) Sebuah DSS (Decision Support System) merupakan "Sebuah sistem berbasis computer yang membantu proses pengambilan keputusan."

Turban (1995) mendefinisikan DSS dengan lebih spesifik sebagai "sebuah sistem informasi berbasis computer yang interaktif, fleksibel, dan dapat diadaptasikan, dikembangkan secara khusus untuk mendukung solusi masalah manajemen yang tidak terstruktur untuk peningkatan pengambilan keputusan yang lebih baik. DSS 
dapat mengutilisasi data, menyediakan interface yang mudah digunakan, dan memungkinkan si pembuat keputusan untuk memberi wawasannya sendiri."

Keen dan Scott Morton (1978) mengungkapkan bahwa ,sebuah DSS mengelompokan sumber daya intelektual dari individual - individual dengan kemampuan komputer untuk meningkatkan kualitas keputusan ("DSS adalah dukungan berbasis komputer untuk pembuat keputusan manajemen yang berurusan dengan masalah semi - terstruktur").

Menurut Sprague dan Carlson (1982), DSS adalah "sistem berbasis computer interaktif yang membantu pembuat keputusan untuk mengutilisasi data dan model untuk menyelesaikan masalah tidak terstruktur."

\section{B. Analytical Hierarcy Process (AHP)}

AHP merupakan suatu model pendukung keputusan yang dikembangkan oleh Thomas L. Saaty. Model pendukung keputusan ini akan menguraikan masalah multi faktor atau multi kriteria yang kompleks menjadi suatu hirarki, menurut Saaty (1993), hirarki didefinisikan sebagai suatu representasi dari sebuah permasalahan yang kompleks dalam suatu struktur multi level dimana level pertama adalah tujuan, yang diikuti level faktor, kriteria, sub kriteria, dan seterusnya ke bawah hingga level terakhir dari alternatif. Dengan hirarki, suatu masalah yang kompleks dapat diuraikan ke dalam kelompok-kelompoknya yang kemudian diatur menjadi suatu bentuk hirarki sehingga permasalahan akan tampak lebih terstruktur dan sistematis.

\section{Waterfall}

Menurut Pressman (2010), model waterfall adalah model klasik yang bersifat sistematis, berurutan dalam membangun software. Nama model ini sebenarnya adalah "Linear Sequential Model". Model ini sering disebut dengan "classic life cycle" atau model waterfall. Model ini termasuk kedalam model generic pada rekayasa perangkat lunak dan pertama kali diperkenalkan oleh Winston Royce sekitar tahun 1970 sehingga sering dianggap kuno, tetapi merupakan model yang paling banyak dipakai didalam Software Engineering (SE). Model ini melakukan pendekatan secara sistematis dan berurutan. Disebut dengan waterfall karena tahap demi tahap yang dilalui harus menunggu selesainya tahap sebelumnya dan berjalan berurutan.

\section{XAMPP}

XAMPP adalah perangkat lunak bebas, yang mendukung banyak sistem operasi, merupakan kompilasi dari beberapa program. Fungsinya adalah sebagai server yang berdiri sendiri (localhost), yang terdiri atas program Apache HTTP Server, MySQL database, dan penerjemah bahasa yang ditulis dengan bahasa pemrograman PHP dan Perl. Nama XAMPP merupakan singkatan dari X (empat sistem operasi apapun), Apache, MySQL, PHP dan Perl. Program ini tersedia dalam GNU General Public License dan bebas, merupakan web server yang mudah digunakan yang dapat melayani tampilan halaman web yang dinamis.

Menurut Yogi wicaksono (2008:7) "XAMPP adalah sebuah software yang berfungsi untuk menjalankan website berbasis PHP dan menggunakan pengolah data MySQL dikomputer local'. XAMPP berperan sebagai server web pada komputer anda. XAMPP juga dapat disebut sebuah CPanel server virtual, yang dapat membantu anda melakukan preview sehingga dapat memodifikasi website tanpa harus online atau terakses dengan internet.

\section{E. MySQL}

MySQL termasuk ke dalam jenis software pada Relational Database Management System (RDBMS) pada sebuah manajemen database sebagai basis data. Pada sebuah perusahaan misalnya, penggunaan sistem informasi dilakukan untuk menyimpan banyak data yang jumlahnya tidak terbatas. Lalu data tersebut dapat diolah untuk kepentingan tertentu secara sedemikian rupa untuk kebutuhan tersebut.

\section{METODE PENELITIAN}

\section{Identifikasi Masalah}

I.I. Pengadaan bahan baku pada PT. Indofood masih dilakukan secara manual, keputusan pengadaan bahan baku masih berdasarkan kebiasaan atau adanya kontrak dengan produsen bahan baku tertentu.

I.2.. Perusahaan tidak dapat mengetahui jika ada produsen lain yang mungkin akan lebih menguntungkan dalam peningkatan kwalitas, karena tefokus pada satu perusahaan yang menjadi langganannya.

\section{Pengumpulan Data}

\subsection{Wawancara}

wawancara dilakukan dengan wawancara terhadap bapak Suprianto selaku karyawan/kepala gudang, bapak Ferdinandus Nong selaku kepala pada bagian pengadaan bahan baku dan bapak Adi Budin selaku manager bagian pengadaan bahan baku.

2.2 Analisa Kebutuhan

Dalam sistem ini, user mengharapkan mendapatkan pendukung keputusan secara sistematis untuk membantunya dalam mengambil suatu keputusan.

\section{Perancangan Sistem}

\subsection{Waterfall}

Waterfall Model, dimana dalam proses pengerjaan tahap yang dilalui harus menunggu selesainya tahap sebelumnya dan berjalan berurutan. Tahapan-tahapannya yaitu komunikasi, perencanaan, pemodelan, konstruksi, dan pengujian.

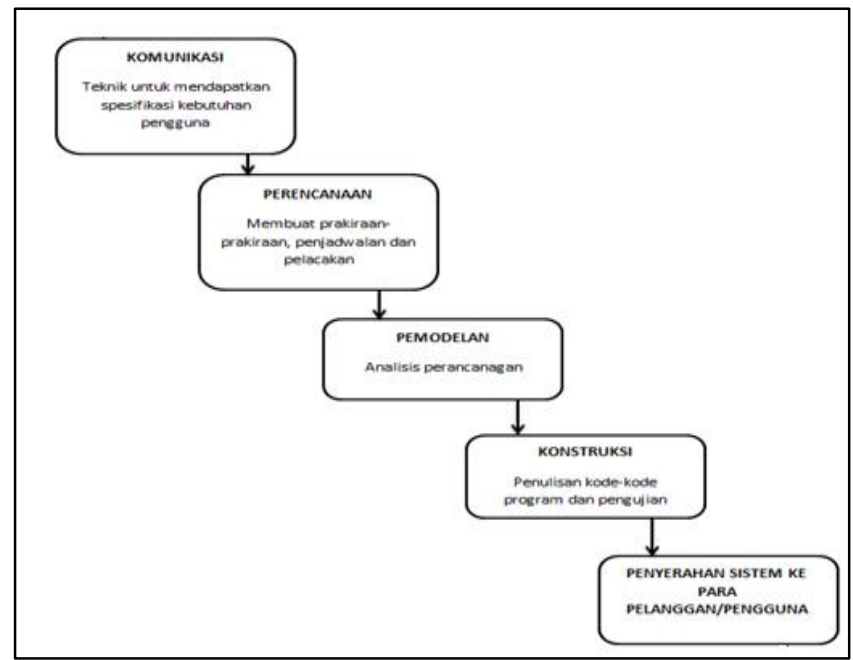

Gambar 1. Waterfall 


\subsection{Use Case Diagram}

Use case diagram dirancang untuk menunjukkan secara umum fungsi dan tanggung jawab aktor dalam Sistem Pendukung Keputusan yang dibangun. Use Case diagram dari Sistem pengambilan keputusan pengadaan raw material pembuatan mie instan.

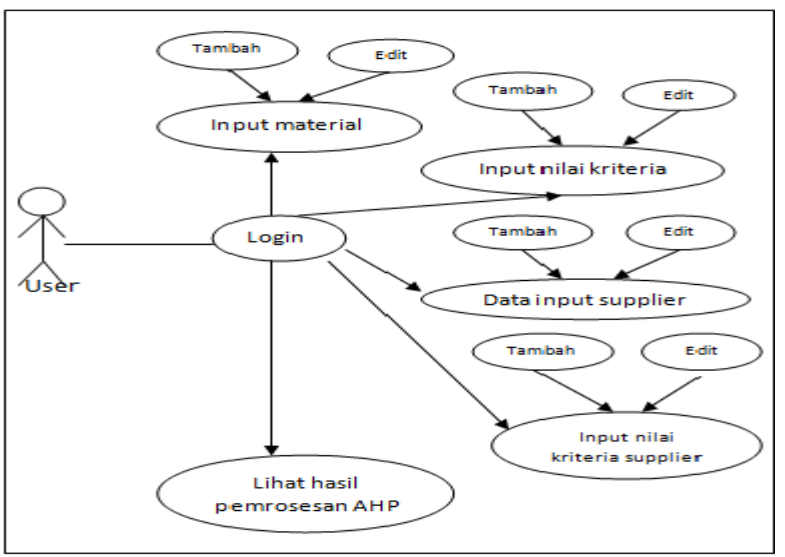

Gambar 2. UseCase Diagram

\section{HASIL DAN PEMBAHASAN}

\subsection{Metode perhitungan menggunakan Analitical}

\section{Hierarchy Procces (AHP)}

Perbandingan berpasangan dilakukan berdasarkan aturan penilaian bobot kriteria.

Tabel 1. Skala Penilaian perbandingan Berpasangan

\begin{tabular}{|c|c|}
\hline $\begin{array}{c}\text { Tingkat } \\
\text { Kepentingan }\end{array}$ & Definisi \\
\hline 1 & Kedua elemen sama penting \\
\hline 3 & $\begin{array}{l}\text { Elemen yang satu sedikit lebih penting dibanding } \\
\text { elemen yang lain }\end{array}$ \\
\hline 5 & $\begin{array}{l}\text { Elemen yang satu esensial atau sangat penting } \\
\text { dibanding elemen yang lainnya }\end{array}$ \\
\hline 7 & $\begin{array}{l}\text { Elemen yang satu benar-benar lebih penting dari yang } \\
\text { lain }\end{array}$ \\
\hline 9 & $\begin{array}{l}\text { Elemen yang satu mutlak lebih penting dibanding } \\
\text { elemen yang lain }\end{array}$ \\
\hline $2,4,6,8$ & Nilai tengah diantara dua penilaian berurutan \\
\hline kebalikan & $\begin{array}{l}\text { Jika aktivitas I mendapat satu angka dibandingkan } \\
\text { dengan aktivitas } j \text {, maka } \mathrm{j} \text { memiliki nilai kebalikannya } \\
\text { dibandingkan dengan } \mathrm{i}\end{array}$ \\
\hline
\end{tabular}

\subsection{Matrik Perbandingan Berpasangan}

Matrik perbandingan berpasangan dilakukan untuk penilaian perbandingan antara satu kriteria dengan kriteria yang lain.

Tabel 2. Matrik Perbandingan Berpasangan

\begin{tabular}{|c|c|c|c|c|c|}
\hline kriteria & Quality & Cost & Delivery & $\begin{array}{c}\text { Flexibili } \\
\text { ty }\end{array}$ & $\begin{array}{c}\text { Respons } \\
\text { ivness }\end{array}$ \\
\hline Quality & 1 & 3,0 & 5,0 & 7,0 & 7,0 \\
\hline Cost & 0,333 & 1 & 3,0 & 5,0 & 5,0 \\
\hline $\begin{array}{c}\text { Deliver } \\
\text { y }\end{array}$ & 0,2 & 0,333 & 1 & 3,0 & 3,0 \\
\hline $\begin{array}{c}\text { Flexibili } \\
\text { ty }\end{array}$ & 0,142 & 0,2 & 0,333 & 1 & 2,0 \\
\hline $\begin{array}{c}\text { Respons } \\
\text { ivness }\end{array}$ & 0,142 & 0,2 & 0,333 & 0,5 & 1 \\
\hline $\begin{array}{c}\text { JUML } \\
\text { AH }\end{array}$ & 1,819 & 4,733 & 9,666 & 16,5 & 18 \\
\hline
\end{tabular}

Berdasarkan tabel 2 kita akan mencari hasil dari npv ( Normalisasi Priority Vector) dengan cara membagikan nilai tiap baris kriteria dengan jumlah tiap kolom kriteria yg ada pada tabel 2. Hasil dari npv di tampilkan melalui tabel 3 .

Tabel 3. priority vector perbandingan berpasangan

\begin{tabular}{|l|l|l|l|c|c|c|}
\hline & Quality & Cost & Delivery & $\begin{array}{c}\text { Flexibil } \\
\text { ity }\end{array}$ & $\begin{array}{c}\text { Responsi } \\
\text { vness }\end{array}$ & $\begin{array}{c}\text { Priority } \\
\text { vector }\end{array}$ \\
\hline Quality & 0,549 & 0,633 & 0,517 & 0,424 & 0,388 & 0,502 \\
\hline Cost & 0,183 & 0,211 & 0,310 & 0,303 & 0,277 & 0,267 \\
\hline Delivery & 0,109 & 0,070 & 0,103 & 0,181 & 0,166 & 0,126 \\
\hline Flexibility & 0,078 & 0,042 & 0,034 & 0,060 & 0,111 & 0,065 \\
\hline $\begin{array}{l}\text { Responsiv } \\
\text { ness }\end{array}$ & 0,078 & 0,042 & 0,034 & 0,030 & 0,055 & 0,042 \\
\hline $\begin{array}{l}\text { JUMLA } \\
\text { H }\end{array}$ & 1,819 & 4,733 & 9,666 & 16,5 & 18 & 5,301 \\
\hline
\end{tabular}

Dari tabel 3 di dapatkan hasil sebagai berikut:

$\lambda$ maks (Principal Eigen Value $)=5,301$

Dari tabel uji perbandingan berpasangan diatas digunakan untuk menguji pembobotan jika sudah konsisten. Dengan cara:

$(\mathrm{CR})<=0,1$.

Jika nilai $\mathrm{CR}>0,1$ maka matrik perbandingan berpasangan harus dihitung ulang.

Hasil perhitungan CI dengan jumlah kriteria (n) adalah 5, sebagai berikut:

CI $((\lambda$ maks-n $) / \mathrm{n}-1)$

CI $(5,301-5) / 5-1)=0,301 / 4=0,753$

$\mathrm{CI}=0,753$

Menghitung nilai CR dengan cara sebagai berikut:

$\mathrm{CR}(\mathrm{CI} / \mathrm{IR})$

$\mathrm{CR}=0,7531476 / 1,12$

$\mathrm{CR}=0,06724532$

Jadi pengujian perbandingan berpasangan untuk menguji pembobotan sudah konsisten atau bisa diterima karena nilai consistency ratio $=0,067$ atau nilai $(\mathrm{CR})<=0,1$ 


\section{Gambar 5. Halaman Data Supplier}

\subsection{Interface Sistem}

A. Tampilan Login

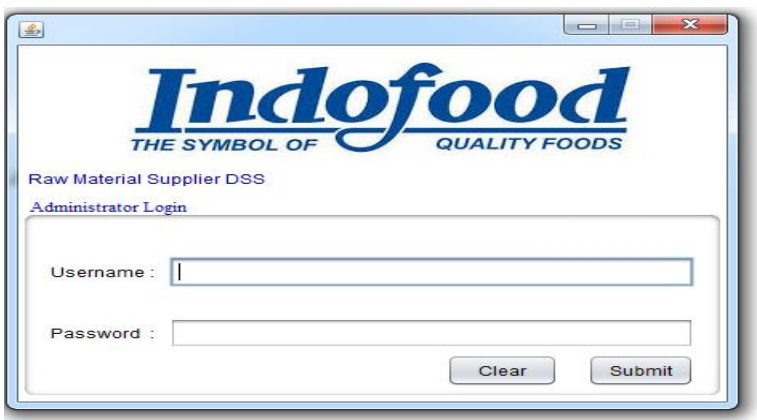

Gambar 3. Tampilan Login

Halaman login adalah form pengisian untuk mengisi username dan password agar dapat masuk pada halaman utama admin. Untuk pemrosesan data, Admin harus melakukan $\log$ in terlebih dahulu. Jika username dan password benar dan terdaftar di tabel login database raw material maka class koneksi data base akan mengirim notifikasi bahwa login berhasil dan jika log in gagal, akan muncul pesan dan Admin akan tetap berada di halaman $\log$ in . setelah berhasil, maka Admin akan memasuki halaman selanjutnya yaitu halaman Data Material. Halaman data material dapat dilihat pada gambar selanjutnya.

\section{B. Data Material}

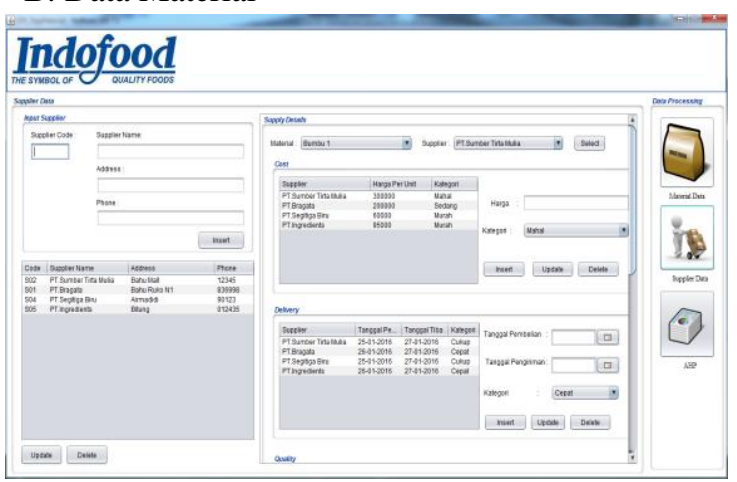

Gambar 4. Halaman Data material

Setelah berhasil log in, maka halaman selanjutnya adalah halaman data material. Pada halaman ini Admin dapat menginput, menghapus dan merubah data material yang akan digunakan. Data input material berupa kode material, nama material, dan bilangan satuan material. Semua data tersebut disimpan dalam tabel data material. Kolom supplier pada tabel material akan diisi/update secara otomatis setelah proses sistem pengambilan keputusan AHP selesai melakukan perankingan supplier untuk material tersebut.

\section{Data Supplier}

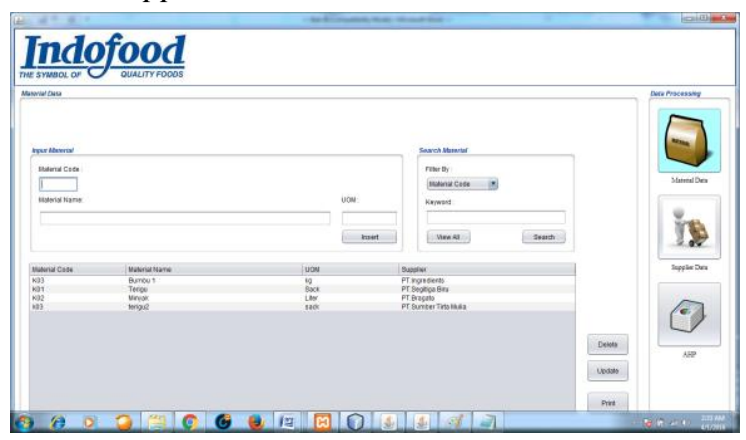

Halaman data supplier, pada halaman ini Admin dapat menginput data supplier baru penyedia bahan baku ke perusahaan. Pada halaman supplier ada beberapa data yang harus di input yaitu kode supplier, nama supplier, alamat supplier dan no telpon supplier. Pada gambar halaman data supplier 4.3 dan 4.4 dapat dilihat ada tabel supply details, tabel supply details menampilkan data untuk menginput nilai dari beberapa kriteria dari jenis bahan material yang sama dengan perbandingan supplier yang berbeda. Kriteria kriteria tersebut mancakup cost, delivery, quality, fleksibilitas dan responsiveness. Informasi umum supplier disimpan dalam tabel database data supplier sedangkan tabel kriteria supplier disimpan dalam tabel data base quality, cost, delivery, flexibility dan responsivnes.

\section{Perhitungan Bobot Alternatif}

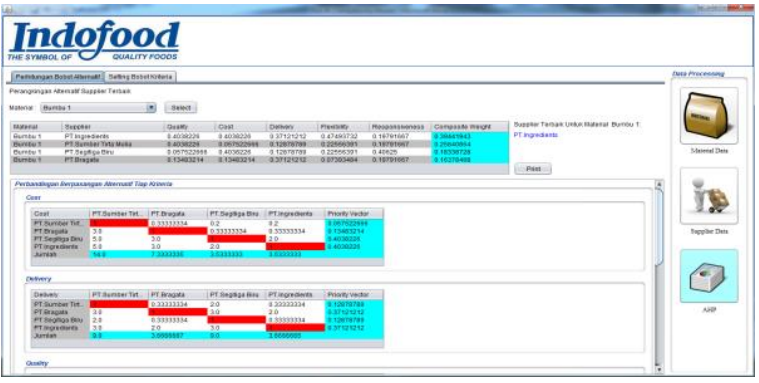

Gambar 6. Halaman Perhitungan Bobot Alternatif

Halaman perhitungan bobot alternatif. Bobot yang ada pada tabel per kriteria adalah hasil perbandingan input per supplier pada halaman supplier dan disimpan dalam tabel database perbandingan berpasangan kriteria. Bobot tersebut kemudian dihitung dengan rumus AHP sehingga hasilnya ditampilkan pada tabel overall composite weight yang mengurutkan nilai supplier berdasarkan perangkingan nilai composite weight. Supplier pada posisi teratas pada tabel perangkingan adalah supplier terbaik.

\section{E. Setting Bobot Kriteria}

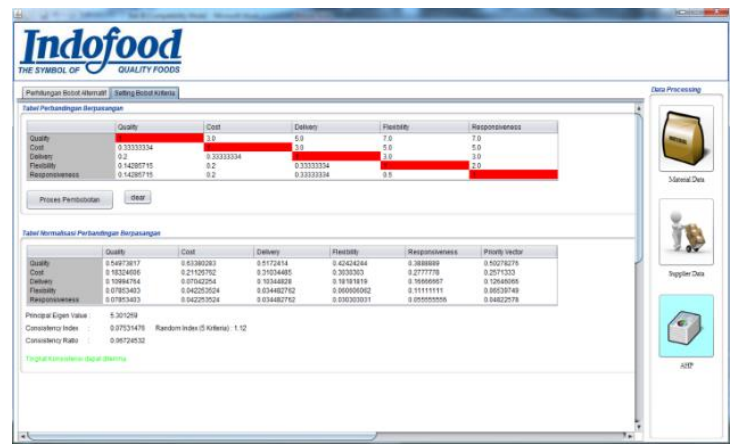

Gambar 7. Halaman Setting Bobot kriteria

Halaman setting bobot kriteria, pada halaman ini bobot kriteria di input langsung kedalam tabel. Nilai input menggunakan standar nilai AHP mulai dari normalisasi perbandingan kriteria berpasangan yang disimpan dalam tabel database normalisasi berdasarkan hasil perhitungan normalisasi di tabel perbandingan kriteria berpasangan untuk mendapatkan priority vector, principal eigen value, consistency index, dan consistency ratio yang kemudian disimpan dalam tabel Consistency. Hasil perhitungan bobot 
consistency ratio akan menentukan apakah bobot kriteria tersebut dapat digunakan untuk setiap alternattif.

\section{PENUTUP}

\section{A. Kesimpulan}

Berdasarkan penelitian yang telah dilakukan dalam membangun sistem pendukung keputusan pengadaan raw material menggunakan metode AHP, dapat ditarik kesimpulan antara lain :

1. Dari hasil wawancara yang telah dilakukan, dibutuhkan sebuah standar yang objektif dalam membantu pengambilan keputusan pengadaan raw material pembuatan mie instan pada PT. INDOFOOD CPB SUKSES MAKMUR.

2. Sistem pendukung keputusan pengadaan raw material pembuatan mie instan dengan metode AHP dapat secara objektif membantu pengambilan keputusan pengadaan raw material berdasarkan kriteria - kriteria yang dapat dengan dinamis dimodifikasi (tambah,hapus,perbarui) berdasarkan kebutuhan dan menggunakan metode yang sistematis untuk menentukan pilihan supplier raw material.

\section{B. Saran}

Berdasarkan hasil penelitian dan kesimpulan mengenai sistem pendukung keputusan pengadaan raw material pembuatan mie instan menggunaka metode AHP, maka diajukan saran sebagai berikut:

1) Sistem pendukung keputusan pengadaan raw material pembuatan mie instan menggunakan metode AHP ini menjadi bagian dari proses penentuan pengambilan keputusan raw material dari supplier terbaik yang lebih objektif dan transparan.

2) Penelitian terhadap pengembangan dan implementasi Sistem pendukung keputusan pengadaan raw material pembuatan mie instan menggunakan metode AHP disarankan untuk dilanjutkan dengan aspek penelitian lainnya dalam hal kajian yang lebih luas, seperti pengaruh,efektivitas dan keakuratan metode dan hasil implementasinya

\section{DAFTAR PUSTAKA}

1. Aditya, W. 2005 Sistem Pendukung Keputusan Dengan Menggunakan Metode AHP Untuk Pembelian Barang. Yogyakarta: I1kom FMIPA UGM

2. Andika Wahyudi Putra, Putu.2009. Rancang Bangun Sistem Pendukung Keputusan Pemilihan Kamera Digital dengan Metode Analytical Hierarchy Process dan TOPSIS Berbasis Web. Surabaya : STIKOM. Diakses pada tanggal 7 april 2016, dari http://digilib.stikom.edu/detil.php?id=642\&q

3. Dadan, U. D. 2001. Sistem Pendukung Keputusan. Jakarta : Elex Media Komputindo.

4. Finlay, dkk (1994). Decision Support System.

5. Kusrini. 2007. Konsep Dan Aplikasi Sistem pendukung Keputusan. Yogyakarta: C.V Andi Offset.
6. Kendall, J.E. \& Kendall, K.E.2010. Analisis dan Perancangan Sistem. Jakarta: Indeks.

7. Roger S. Pressman, Ph. D.2010. Rekayasa Perangkat Lunak. Yogyakarta: Penerbit ANDI.

8. Saliman,2010. Mengenal Decision Support System (DSS).

9. Sunarto. 2011. Sistem Pendukung Keputusan Pemilihan Handphone Metode Analithical Hierarchy Process (AHP) Berbasis PHP.

10. Turban (1995), Decision Support System.

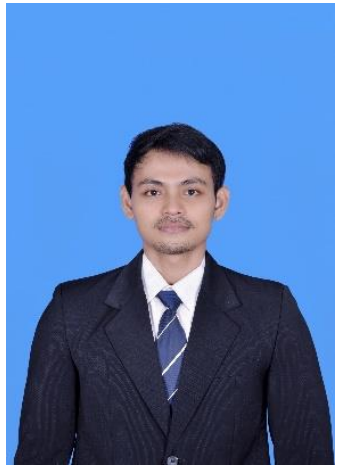

Sekilas dari penulis dengan lengkap nama Dzulkifli Fitriana, lahir di Bitung, Provinsi Sulawesi Utara, anak pertama dari empat bersaudara. Dengan pendidikan sekolah dasar impress 10/73 Bitung. Kemudian melanjutkan ke Sekolah Menengah Pertama Negeri 2 Bitung. Kemudian melanjutkan ke Sekolah Menengah Kejuruan (SMK) Negeri 2 Bitung. Setelah lulus tahun 2010 melanjutkan ke Perguruan Tinggi di Universitas Sam Ratulangi manado dengan mengambil Jurusan Teknik Informatika. Pada tanggal 3 Oktober 2016 penulis resmi Lulus di Teknik Informatika Universitas Sam Ratulangi dan menyandang gelar Sarjana Komputer. 